\title{
Vínculo Amoroso Homoafetivo e Psicanálise: Um Estudo Qualitativo
}

\author{
Gustavo Chagas Oliveira ${ }^{1}$ \\ Orcid.org/0000-0002-6596-6004 \\ Maíra Bonafé Sei*, 1 \\ Orcid.org/0000-0003-0693-5029
}

${ }^{1}$ Universidade Estadual de Londrina, Londrina, PR, Brasil

\section{Resumo}

A contemporaneidade abarca diversas formas de conjugalidade e dentre elas encontra-se o relacionamento entre pessoas do mesmo sexo. Há diversos estudos sobre a homoafetividade e parentalidade homoafetiva, contudo poucos dão ênfase à investigação da conjugalidade destes casais, em especial a partir do referencial psicanalítico. Objetivou-se, assim, analisar a conjugalidade homoafetiva por meio do referencial da Psicanálise de Casal e Família, com foco na tipologia vincular e influência da transmissão psíquica geracional. Delineou-se como um estudo clínico-qualitativo, por meio do qual foram entrevistados quatro casais, sendo dois casais de mulheres e dois casais de homens, o tempo de relacionamento variou entre 3 e 11 anos. Pode-se perceber a incidência de uma tipologia vincular de terceiridade, evidenciando a capacidade destes casais de não idealizarem o vínculo, intercambiando diferentes significados acerca da relação. Observou-se também a influência da transmissão psíquica geracional, incentivando os membros dos casais, através de alianças psíquicas, a constituírem modelos conjugais próprios elaborados das gerações precedentes. Novos estudos que visem a compreensão do vínculo conjugal homoafetivo devem ser realizados.

Palavras-chave: Casais homoafetivos, vínculo, transmissão psíquica.

\section{Homoaffective Loving Bond and Psychoanalysis: A Qualitative Study}

\begin{abstract}
Contemporaneity encompasses several forms of conjugality, among them the relationship between people of the same sex. There are several studies on homoaffectivity and homoaffective parenting, however, few emphasize the investigation of the conjugality of these couples, especially from the psychoanalytic framework. The aim of this study was to analyze the homoaffective conjugality through the Couple and Family Psychoanalysis framework, with a focus on the bond typology and influence of generational psychic transmission. This was a clinical-qualitative study, in which four couples were

* Endereço para correspondência: Rua Shangai, 55, ap. 14-B, Jardim Claudia, Londrina, PR, Brasil 86050-350. E-mail: mairabonafe@gmail.com

Apoio financeiro: Fundação Araucária; Conselho Nacional de Desenvolvimento Científico e Tecnológico (CNPq).
\end{abstract}


interviewed, these being two pairs of women and two pairs of men, with lengths of relationship ranging from 3 to 11 years. The incidence of a bond typology of thirdness could be perceived, evidencing the capacity of these couples not to idealize the bond, exchanging different meanings about the relationship. The influence of generational psychic transmission was also observed, encouraging the members of the couples, through psychic alliances, to form their own conjugal models elaborated from previous generations. New studies aimed at the comprehension of the homoaffective conjugal bond should be carried out.

Keywords: Homoaffective couples, bond, psychic transmission.

\section{Vínculo Amoroso Homoafetivo y el Psicoanálisis: Un Estudio Cualitativo}

\section{Resumen}

La contemporaneidad abarca diversas formas de matrimonio y entre ellos es la relación entre personas del mismo sexo. Hay variados diversos estudios sobre la homoafetividad y la parentalidad homoafectiva, pero pocos ponen énfasis en la investigación de la conyugalidad de estas parejas, en especial a partir del referencial psicoanalítico. Se objetivó, así, analizar las relaciones conyugales homosexuales a través del marco de Pareja y Familia Psicoanálisis, con foco en la tipología vincular e influencia de la transmisión psíquica generacional. Se perfila como un estudio clínico-cualitativo, a través del cual los encuestados eran cuatro parejas, dos parejas de mujeres y dos parejas de hombres con relación oscilaron entre 3 y 11 años. Se puede ver la incidencia de un tipo de enlace de la terceridad, lo que indica la capacidad de estas parejas no idealizar la conexión, intercambiando diferentes significados en la relación. También señaló la influencia de la transmisión psíquica generacional, animando a los miembros de las parejas, a través de alianzas psíquicas, constituyen propios modelos maritales desarrollados a partir de las generaciones anteriores. Los nuevos estudios que busquen la comprensión del vínculo conyugal homoafectivo deben ser realizados.

Palabras clave: Parejas homosexuales, vínculo, transmisión psíquica.

A contemporaneidade favorece o aparecimento de configurações conjugais mais flexíveis e igualitárias. Tal favorecimento se dá por meio de transformações sociais e políticas que buscam dar voz às populações que ainda necessitam de visibilidade e direitos, como é o caso da população LGBT (Lésbicas, Gays, Bissexuais, Travestis e Transgêneros). No Brasil, a união estável homoafetiva foi reconhecida em maio de 2011 pelo Superior Tribunal Federal (STF) e pelo Superior Tribunal de Justiça (STJ). Com esta decisão os cartórios passaram a realizá-la, bem como convertê-la em casamento civil. Apenas em maio de 2013 o Conselho Nacional de Justiça (CNJ), por meio da resolução $\mathrm{n}^{\circ} 175$ de $14 / 05 / 2013$, passou a obrigar todos os cartórios a oficializarem o casamento civil homoafetivo.
É possível encontrar na literatura recente, publicada no cenário nacional, variados estudos discorrendo a respeito das relações homoafetivas sob a luz do Direito (Lima, 2014; Ramos; Benigno, 2013; Vareschini, 2009). Há pesquisas que visam discorrer sobre famílias homoafetivas de forma mais ampla (Lira \& Morais, 2016; Nascimento, 2015; Rodriguez \& Gomes, 2012; Vilhena, Souza, Uziel, Zamora, \& Novaes, 2011), acerca de questões concernentes à homoparentalidade masculina (Gato \& Fontaine, 2014; Santos, Scorsolini-Comim, \& Santos, 2013) ou que almejam compreender o processo de adoção por casais homoafetivos (Cecílio, Scorsolini-Comin, \& Santos, 2013; CerqueiraSantos \& Santana, 2015; Lira, Morais, \& Boris, 2015; Rodriguez, Gomes, \& Oliveira, 2017). 
Encontram-se, ademais, investigações acerca do processo de revelação da orientação sexual homossexual (Defendi, 2010; Silva, Frutuozo, Feijó, Valerio, \& Chaves, 2015), da influência da heteronormativiade na conjugalidade (Esteca, 2016), maternidade de lésbicas (Pontes, FéresCarneiro, \& Magalhães, 2015; Santos \& Gomes, 2016) e representação parental em casais homoafetivos masculinos (Rodriguez, Merli, \& Gomes, 2015).

Todavia são escassos os estudos a respeito especificamente da conjugalidade entre pares homoafetivos (Féres-Carneiro, 1997; Kurdek, 2004, 2005; Lomando, Wagner, \& Gonçalves, 2011), especialmente aqueles empreendidos a partir do referencial da Psicanálise de Casal e Família. Sobre os estudos acerca da conjugalidade entre casais homossexuais no cenário nacional, Rodrigues e Boeckel (2016) encontraram apenas sete artigos, apontando que as investigações ainda objetivam "conhecer e descrever atitudes, convicções e princípios de seus participantes" (p. 106). Nascimento, Scorsolini-Comin, Fontaine e Santos (2015), por meio de revisão da literatura internacional, apontaram para a necessidade de se realizar pesquisas empíricas com este público, com foco nas particularidades dos casais homoafetivos, a despeito de estudos comparativos que poderiam reforçar um olhar pautado na heteronormatividade.

No que se refere à intersubjetividade, Puget e Berenstein (1993) defendem haver um espaço psíquico intersubjetivo, no qual ". . . privilegia-se o vínculo como uma estrutura que liga duradouramente, abrange e envolve os egos. Envolve pelo menos dois ou mais e o contexto definido recorta o significado específico dos egos ligados" (p. xi). Quanto à definição de vínculo, pode-se dizer que se trata de

uma estrutura de três termos, constituída por dois pólos, os dois egos (descritos a partir de um observador virtual), ou um ego e outro (visto a partir de si mesmo) e um conector (ou intermediário) que dará conta de ligar ambos. (Puget \& Berenstein, 1993, p. 18)

Para Kaës (2011), vínculo refere-se a um “. . . movimento mais ou menos estável dos investimentos, das representações e das ações que associam dois ou mais sujeitos para a realização de seus desejos" (p. 159). Pressupõe um trabalho psíquico, ou seja, o indivíduo necessita investir libidinalmente no vínculo e no outro, estando o vínculo ligado ao que se chama de espaço intersubjetivo. Em contrapartida, as escolhas amorosas relacionam-se ao chamado espaço intrasubjetivo, que diz respeito ao mundo interno e suas relações com o objeto (Puget \& Berenstein, 1993).

Freud em seu artigo "Sobre o Narcisismo" (1914/1996) postula a existência de dois tipos de escolha amorosa objetal, a narcísica e a anaclítica. A escolha narcísica está intimamente ligada com a eleição de alguém que represente o próprio sujeito como objeto amoroso. $\mathrm{O}$ indivíduo busca no outro o que ele mesmo é, foi, gostaria de ser ou alguém que fez parte dele mesmo. Por outro lado, a escolha anaclítica se refere a uma busca pelo objeto perdido na infância, fazendo com que o indivíduo procure no cônjuge a representação de quem o protegeu, alimentou e investiu libidinalmente. Tais apontamentos de Freud (1914/1996) centram-se em aspectos intrapsíquicos, enquanto que a ideia de vínculo se pauta em uma perspectiva intersubjetiva, ampliando a complexidade em torno da compreensão da conjugalidade.

Kaës (2014) discute o tema da vinculação entre os indivíduos, por meio da discussão acerca das alianças inconscientes, que podem ter um caráter estruturante, defensivo ou ofensivo, destacando o papel do negativo na formação das alianças. Puget e Berenstein (1993) discorrem sobre os acordos e pactos inconscientes e indicam que

os acordos inconscientes são resultado de um tipo de combinação entre aqueles aspectos compartilháveis, partindo de cada um dos espaços mentais dos sujeitos, e resultam do desdobramento da tendência de unificar seus funcionamentos mentais e vinculares. ... Os pactos inconscientes, tendem a especificar elementos diferentes, provenientes do espaço mental incompartilhável de cada ego. Compartilhar o incompartilhável obriga os egos a realizar uma série de concessões, para, dessa maneira, pactuar, fazer o 
desejo do outro, colocando-se em posição favorável. (p. 21)

O casal firma um contrato inconsciente por meio dos acordos e pactos, e estes estabelecem como funcionarão as relações intersubjetivas do casal. Puget e Berenstein (1993) estabelecem, ademais, 3 tipos de tipologias vinculares: dual, terceiridade ampla e terceiridade limitada.

A estrutura dual se refere àquela na qual os indivíduos se inserem em um vínculo dominado pela fusão do casal, "dominado pela idealização mútua de algum componente, em sua maioria parcial" (p. 35). A terceiridade limitada se caracteriza por já possuir um terceiro na relação, mas que ainda mantém um lugar de excluído, "há um vínculo dual indiscriminado, mas já não auto-suficiente, porém produtor de angústia catastrófica, evitada pela presença do terceiro" (p. 42). A terceiridade ampla, por sua vez, evidencia um vínculo com duas mentes discriminadas, onde ". . . ambas possuem uma representação interna do outro, configurada para que não seja preciso referir-se permanentemente ao outro, para se sentir incluído" (p. 47).

Contudo, para entender os relacionamentos conjugais e seus intercâmbios psíquicos, é necessário da mesma maneira considerar que os casais carregam consigo a história de suas famílias, ou seja, possuem uma herança psíquica familiar. Desde Freud (1914/1996) já se sabe sobre a importância das expectativas parentais depositadas na próxima geração. Naquilo que o autor nomeou de "Sua Majestade o Bebê", o narcisismo parental aponta à criança o lugar que ela deverá ocupar para concretizar o que a geração passada não conseguiu, para tanto "a criança realizará os sonhos dourados que os pais jamais realizaram" (Freud, 1914/1996, p. 98).

Com base na formulação freudiana acerca do narcisismo parental, Aulagnier (1979) formula o conceito de "contrato narcisista". Este contrato, efetivado entre pais e filhos, proporciona uma ligação entre as gerações e garantem sua continuidade. Monti (2008) afirma que tal contrato tem a função de assegurar a origem do indivíduo, manter a continuidade entre as gerações, possibilitando o desenvolvimento e garantindo um lugar ao bebê.
Para compreensão acerca das influências engendradas pelas gerações precedentes na vida de um indivíduo e do casal, entende-se ser pertinente discorrer sobre o conceito de transmissão psíquica geracional, que pode ser dividida em duas classes: a transmissão psíquica intergeracional e transgeracional (Scorsolini-Comin $\&$ Santos, 2016). A primeira está ligada às heranças psíquicas conscientes e, como tal, com possibilidades de elaboração, com a transmissão acontecendo entre as gerações. Diferentemente, a segunda refere-se ao material transmitido de forma inconsciente, bruta e sem elaboração, usualmente vinculados a situações traumáticas e que são transmitidas através das gerações.

Ressalta-se que existem variados estudos acerca das implicações da transmissão psíquica geracional na conjugalidade, como nas situações nas quais a conjugalidade surge antes da parentalidade (Merli, 2012), sobre a influência da transmissão psíquica no estabelecimento do vínculo conjugal (Paiva \& Gomes, 2012), considerações sobre este fenômeno na parentalidade de casais homoafetivos (Rodriguez et al., 2015; Santos \& Gomes, 2016), e até estudos acerca de indivíduos que optam pela não construção de um vínculo amoroso (Zanetti \& Gomes, 2013). Contudo, nem sempre há um foco na transmissão psíquica de casais na conjugalidade não atrelada ao exercício de funções parentais.

Esteca (2016), em contrapartida, buscou compreender os impactos da heteronormatividade em mulheres lésbicas, sem filhos, que haviam rompido um vínculo conjugal homoafetivo. A pesquisadora observou que as participantes sofreram problemas de rejeição da família devido à orientação sexual, bem como notou a influência da transmissão psíquica na relação entre as concepções familiares acerca da homossexualidade e as decisões concernentes à vida amorosa das entrevistadas.

Tendo em vista a existência de estudos que apontam para semelhanças nos índices de saúde de casais homoafetivos quando comparados com casais homossexuais, com a construção de relacionamentos duradouros (Kurdek, 2004), objetivou-se analisar a conjugalidade homoafetiva em casais homoafetivos de homens e mulhe- 
res. Buscou-se, assim, por meio de uma análise vincular, pautada no referencial psicanalítico, investigar quatro casais homoafetivos e discutir a tipologia vincular instaurada e parâmetros definitórios do casal (Puget \& Berenstein, 1993), além das alianças inconscientes estabelecidas (Kaës, 2014) e influência da transmissão psíquica geracional (Scorsolini-Comin \& Santos, 2016).

\section{Método}

Trata-se de um estudo clínico-qualitativo que visa o aprofundamento acerca do tema pesquisado, sem focar a quantificação de dados e análise estatística dos mesmos, com o intuito de se investigar os sentidos e significados dos fenômenos (Turato, 2003). Configura-se como uma estratégia que faz uso de conceitos da psicanálise para delineamento da pesquisa, coleta dos dados e interpretação dos resultados. Neste tipo de investigação, tanto se valoriza a existência de angústias e ansiedades nos participantes da pesquisa, quanto se compreende que "são também as próprias angústias e ansiedades do pesquisador que igualmente o movem para querer entender as leis das manifestações humanas" (Turato, 2003, p. 252).

\section{Participantes}

Participaram quatro casais homoafetivos, dois casais constituídos por mulheres e outros dois casais constituídos por homens, em consonância com o estudo de Munhoz (2017), que também trabalho com os dados advindos de quatro casais. Buscou-se uma variedade de tipos (Turato, 2003), ao se entrevistar casais de homens e mulheres, mas com respeito à dimensão metodológica do estudo, de caráter mais exploratório (Fontanella \& Magdaleno, 2012) e com vistas ao maior aprofundamento na análise dos relatos dos participantes. As idades variaram entre 25 e 44 anos e o tempo de relacionamento variou entre 3 e 11 anos. Estabeleceu-se como critério de inclusão o tempo mínimo de 3 anos de relacionamento (Merli, 2012), sem critérios de exclusão quanto à classe social, raça ou religião. Todos os nomes utilizados na pesquisa são fictícios, de modo a preservar a identidade dos participantes.

\section{Coleta de Dados}

Fez-se um convite para participação na pesquisa em uma rede social tanto no perfil dos autores deste estudo quanto em grupos diversos, esclarecendo os objetivos da pesquisa e perfil dos participantes, tendo-se estabelecido, em decorrência dos prazos acadêmicos, o período de seis meses para a coleta de dados. Após o contato dos interessados, as entrevistas foram agendadas e realizadas de maneira conjunta, com a participação de ambos os cônjuges (Merli, 2012; Munhoz, 2017). Tal estratégia foi utilizada a partir da concepção de espaço psíquico intersubjetivo (Puget \& Berenstein, 1993), por meio da qual compreende-se que o vínculo poderá ser analisado se um estiver na presença do outro. As entrevistas em questão foram gravadas e transcritas para análise dos dados. O tempo de entrevista variou entre $1 \mathrm{~h} 15 \mathrm{~min}$ e $48 \mathrm{~min}$.

\section{Instrumentos}

Foi utilizado um roteiro semi-dirigido de entrevista (Merli, 2012) para a coleta de dados, que incluía perguntas relativas à história do casal, escolha do(a) parceiro(a), dinâmica de relacionamento do casal, dos pais e avós, além de questões concernentes à reação da família frente à relação do casal.

\section{Análise de Dados}

A análise dos dados foi realizada em dois momentos diferentes, com interpretação do material pautada no método psicanalítico, que propõe atenção ao campo intersubjetivo estabelecido nas entrevistas (Zanetti, 2013). Partiu-se, ademais, de uma análise individual de cada entrevista a partir categorias definidas a priori (Moraes, 2003) tendo em vista o referencial psicanalítico vincular adotado, que relacionavam ao histórico do casal, dados referentes ao relacionamento conjugal e histórico das famílias de origem. Tal divisão visou contemplar discussões concernentes à tipologia vincular, dinâmica conjugal estabelecida e influência da transmissão 
psíquica geracional na conjugalidade dos casais entrevistados (Merli, 2012). Em um segundo momento, sintetizou-se os dados obtidos em todas as entrevistas a partir de uma discussão única que visou abarcar as percepções obtidas a partir do conjunto dos dados.

\section{Aspectos Éticos}

A pesquisa foi submetida ao Comitê de Ética em Pesquisa com Seres Humanos da Universidade Estadual de Londrina e foi aprovada por meio do parecer 1.031.479, com assinatura do Termo de Consentimento Livre e Esclarecido por parte dos participantes da pesquisa.

\section{Resultados}

Foram entrevistados quatro casais, sendo dois compostos por homens e dois por mulheres. Esperava-se que os próprios interessados fizessem contato com os pesquisadores, contudo, apenas um dos casais entrou em contato diretamente com os responsáveis pela pesquisa. Os demais participantes foram indicados por colegas ou familiares, que obtiveram informações acerca da pesquisa por meio do convite exposto na rede social ou por outras vias de divulgação. As entrevistas foram realizadas na casa dos entrevistados ou nas dependências de uma clínica psicológica universitária, conforme preferência dos participantes.

\section{Casal 1 - Bernardo (27) e Ícaro (29)}

Quanto ao histórico do casal, Bernardo e Ícaro estavam juntos há oito anos e haviam se visto pela primeira vez na rua, quando Bernardo tinha por volta dos 15 anos e Ícaro 17, época em que moravam em cidades vizinhas. Reencontraram-se 4 anos mais tarde, em uma rede social, tendo trocado telefone e ficado juntos desde então.

Sobre a escolha de parceiro, Ícaro afirmou que foi se identificando: "A princípio foi a personalidade dele que me atraiu... O jeito que ele me tratava...". Já Bernardo disse que foi amor: "Quando eu conheci ele, acho que ele estava até namorando e eu também. Ai quando eu conheci ele, eu larguei meu relacionamento e ele também...". Começaram a conversar e três meses depois já estavam com as malas prontas para se mudarem para uma cidade de maior porte.

O começo foi difícil, principalmente para Ícaro, pois ele estava à procura de emprego:

quando eu fui para a entrevista eu fiquei uns dias longe dele e eu senti que sem ele eu não ia conseguir. . . . Ai eu peguei, fiz a entrevista, não descartei o emprego e deixei tudo certo, mas disse para ele que sem ele eu não iria.

Bernardo topou e reafirmou que não conseguiam mais viver separados.

A situação na nova cidade era complicada, uma vez que Bernardo ainda não possuía emprego e não havia lugar para morarem. Decidiram morar na casa de uma tia de Ícaro, religiosa, fato que implicou na necessidade de esconderem a relação. A reação dos familiares e amigos ao relacionamento de Bernardo e Ícaro foi diversa. O pai de Bernardo ficou revoltado com a situação, enquanto que sua mãe se mostrou amiga e aberta, tendo sido melhor do que ele esperava. Ícaro não contou para os pais sobre seu relacionamento até o momento em que ligou para sua mãe e lhe contou, responsabilizando-a por transmitir a notícia para o pai.

Quanto às expectativas que um tinha em relação ao outro, Ícaro afirmou que era bem imaturo e Bernardo indicou que já estava mais certo do que queria para sua vida. Contaram que a vida financeira melhorou e puderam investir em um negócio, com boa condição financeira no momento da entrevista.

Acerca do relacionamento conjugal, apontaram que cresceram ao longo dos anos. Ícaro indicou tratar-se de uma relação amadurecida, com amor, amizade e cumplicidade. Em consonância, Bernardo falou que era um relacionamento respeitoso, exemplar.

Sobre os conflitos enfrentados pelo casal e as vias de resolução, ambos concordaram que a relação estava mediada pela comunicação entre eles. Bernardo indicou haver um equilíbrio entre razão e emoção, enquanto Ícaro ressaltou a importância do diálogo e também do equilíbrio entre elementos como amor, carinho e sexo. 
Discorreram sobre o plano de terem um filho e quando perguntados sobre semelhanças com seus pais, Ícaro disse que se achava um pouco parecido com sua mãe. Contou que seus avós maternos haviam falecido, mas seu avô avisa sido um homem duro, frio, com o acolhimento aos netos tendo sido dado pela avó, mais amorosa. Sobre os avós maternos, apontou para o afeto partilhado entre ambos e para o cuidado de seu avô com a esposa, vista como mais fraca. Por outro lado, em relação aos pais, Ícaro relatou que brigavam bastante, apesar do amor que sentiam um pelo outro, sendo que sua mãe sempre lhe contava das brigas do casal.

Bernardo relatou que, em relação aos avós paternos, não possuía muitos dados, pois o avô faleceu muito cedo, tendo falado, sobre os avós maternos, da existência de brigas constantes e a separação ocorrida quando já eram idosos. Seus pais eram unidos e se amavam bastante, mas já haviam passado por muitos conflitos. Namoravam quando se conheceram, de forma semelhante a Bernardo e Ícaro, estabelecendo um relacionamento que foi permeado por brigas e uso de álcool por parte do pai. Houve episódios de violência, mas na atualidade se davam bem, viajavam e tinham uma relação positiva.

\section{Casal 2 - Alice (44) e Helena (37)}

Sobre o histórico do casal, estavam juntas há 11 anos e haviam se conhecido em um bar por meio de uma amiga em comum. Helena e essa amiga resolveram estudar juntas no apartamento que essa amiga dividia com Alice, de maneira que as duas começaram a se ver com frequência. Alice relatou que desde o primeiro dia em que viu Helena ficou interessada nela. Helena, por sua vez, disse que Alice havia chamado sua atenção, mas que nunca havia estado em um relacionamento com outra mulher.

Alice se movimentou para que elas ficassem sozinhas em um destes encontros e Helena explicou que naquele momento resolveu se entregar ao que estava sentindo. Helena estava inserida em um relacionamento heterossexual antes de conhecer Alice e relatou que o início da relação das duas foi para ela a sensação de "entrar em outro universo".
Quanto à decisão de morarem juntas, Alice explicou que dormiam juntas diariamente, sendo que Helena atribuiu a rapidez em morarem juntas ao fato de serem lésbicas. Alice concordou e disse: "Lésbica já tem sempre uma caixa montada que ela já arrasta pra casa da outra". Helena afirmou que o casal possuía uma "logística que funciona" e Alice indicou que havia um respeito de "espaço e tempo".

Acerca das expectativas para com o relacionamento, Alice apontou que não imaginava algo diferente do que já era. Helena, por outro lado, contou que houve um estranhamento em um primeiro momento, mas que aos poucos foi se "fascinando" por Alice.

Acerca da reação dos familiares ao relacionamento do casal, Alice disse que de sua parte foi tranquilo, visto que seus pais já sabiam de sua orientação sexual desde que ela era adolescente. Da parte de Helena a história se configurou de maneira diferente, com sua mãe tendo reagido mal, especialmente por este entendimento sobre esta relação ter coincidido com o falecimento do pai de Helena. De acordo com ela, "como eu já tinha perdido um irmão de forma trágica anteriormente, foram duas mortes trágicas em um espaço de cinco anos. . . . Depois de um tempo minha mãe foi assimilando". Alice completou dizendo que agora elas tinham a sensação de que a família estava completa.

Quanto ao relacionamento conjugal de uma maneira geral, Alice argumentou que havia muita alegria: "Tem crise, a gente discute um monte de coisa, mas a gente se diverte muito também. . . É uma coisa que flui, uma coisa bem gostosa". Helena completou afirmando: " $A$ gente entendeu em um determinado momento que os movimentos eram diferentes e encontrou espaços em comum para curtir".

Sobre a comunicação entre o casal e os conflitos, Helena explicou que haviam passado por momentos difíceis, mas com o diálogo e a busca da melhor solução para os conflitos vivenciados:

Eu tenho um exercício de falar o que sente. Eu e minha mãe conversamos muito. Temos um hábito de sentar e conversar. A família da Alice já não é de falar... E isso refletiu 
forte nas duas, porque ela hoje ela fala mais.

O casal relatou ter uma dificuldade no tocante a ter ou não filhos, já que Helena desejava ter filho, sem imaginar que não viria a ter: " $E a i$, eu perdi um irmão e perdi um pai também. . . . Além de um desejo de ter filho, eu tive uma sensação de perda de família". Alice, por sua vez, nunca se imaginou tendo filhos e argumentou que: "pensar para mim em ter filho parece que eu vou deixar de viver algumas coisas".

Helena relatou que a construção e manutenção da conjugalidade se relacionava ao cuidado com determinadas questões a serem cultivadas no relacionamento, sem um automatismo da relação, além do respeito aos espaços individuais. Já Alice explicou ser necessário tentar "equilibrar para ficar bem".

Quando indagadas sobre se verem parecidas com os pais em seu relacionamento, Helena afirmou uma identificação no campo da parceria do casal, com um distanciamento deste modelo em decorrência delas não gostarem de brigar, tal como seus pais faziam. Alice relatou que precisava se: "policiar na coisa da minha mãe, ela é muito cuidadora. Às vezes me questiono e acho que algumas coisas são repetidas, mas acho importante enxergar isso. Não passa despercebido".

Sobre as famílias de origem, Alice disse que não possuía muitos dados sobre os avós paternos, pois haviam morrido muito cedo. Conviveu com a avó materna, que sofria com a dureza e agressões verbais por parte do marido visto como um "homem que não conhecia os prazeres da vida". Acerca dos pais, Alice afirmou que formavam um casal "bacana", sem brigas, que realiza atividades juntos, "Um não vive sem o outro". Quanto à Helena, ela afirmou que a família do pai sempre foi mais "forte" que a família da mãe: "Minha vó falava que ela gostava de mandar e meu avô gostava de ser mandado. Ela é a grande matriarca da família, mas levou muita gente pra terapia. Eu inclusive". Acerca dos avós maternos, Helena contou que eles tiveram uma história tumultuada:

ele era um homem machista e ela uma mulher muito boa. Tiveram dois filhos, minha mãe espoleta e meu tio que era gay. Uma coisa atrelada na minha vida. A história da minha mãe é uma sequência de tragédias. $O$ irmão morreu de HIV, ela foi perdendo tudo de forma trágica. Por isso as pessoas ficaram tão bravas com o fato de eu ter virado sapatão.

Sobre os pais, Helena disse que eles se conheceram no ônibus em decorrência dos compromissos de trabalho e estudo. Seu pai apresentava um histórico de depressão, enquanto que a mãe se mostrava sempre vivaz.

Ele se apaixonou por essa coisa dela e ela se apaixonou porque ele era diferente dos homens que ela tinha conhecido. . . . Eram duas pessoas muito intensas e eu falo que não tinha mediador ali... Meu irmão chegou a se suicidar quando tinha 22 anos $e$ eu vejo que foi um percurso da vida lidando com os sustos que meu irmão trazia. Eles se desencontravam... Essa coisa do filho com problema foi tirando o chão do casal. Eles foram discordando um do outro, tanto que quando meu irmão se matou o casamento deles ficou horrivel. Mas eles sempre foram apaixonados, viajaram muito e eu tenho muito isso... Atualmente minha mãe voltou a ser essa pessoa incrivel, mais viva, divertida. Eu não sabia que minha mãe era divertida, meu pai que trazia um pouco de música para casa.

\section{Casal 3 - Miguel (34) e Vicente (31)}

Sobre o histórico do casal, Miguel e Vicente, juntos há seis anos, moravam em cidades vizinhas e se conheceram por meio de uma postagem de um amigo em comum em uma rede social. Inicialmente se viam de quinze em quinze dias. Após 6 meses de namoro, Miguel se mudou para a mesma cidade de Vicente e os dois passaram a viver juntos. Sobre o início do relacionamento, Vicente relatou que se mostrava mais resistente, demorando para assumir seus sentimentos. Já Miguel havia tido dificuldades em aceitar que estava gostando de Vicente, por nunca ter estado em um relacionamento homoafetivo:

A gente é gay desde quando a gente nasce, mas às vezes você reluta. A pior aceitação, 
a mais dificil, foi a minha própria aceitação. ... Ai eu pensei "vou me permitir". Foi quando eu conheci ele, o primeiro e único parceiro que eu tive.

No que se refere às expectativas acerca do relacionamento, Vicente contou que não criava expectativas e buscava não idealizar, de forma semelhante a Miguel, que indicou não ter criado expectativas, tendo ciência sobre como era o relacionamento após seis meses de convivência.

A decisão de morar juntos foi decorrente da necessidade de ficarem juntos na mesma cidade, com Miguel podendo procurar um emprego melhor. Entretanto, "a grande questão de pensar na gente, pensar em um relacionamento futuro, foi quando compramos o apartamento". Até então, o casal dividia as despesas de um apartamento alugado. Quando surgiu a oportunidade de adquirir um apartamento próprio, Miguel recuou: "Fazia só um ano que a gente morava junto. Eu queria comprar o meu, porque se a gente terminasse eu teria o meu".

Sobre a reação dos familiares ao relacionamento, Miguel relutou em contar para os pais, mas afirmou que eles possuíam conhecimento do seu relacionamento com Vicente. Vicente contou que no seu caso já havia comunicado seus pais há algum tempo sobre sua orientação sexual.

O relacionamento conjugal era visto como tranquilo, existindo, entretanto, situações nas quais eles discordavam. Miguel disse: " $A$ gente não briga ... Eu que não tenho muita paciência, às vezes puxo briga, mas ele só escuta, dai eu perco a graça, e não tem graça brigar sozinho, né?". Vicente, por sua vez, afirmou: "A gente não tem estresse. Eu vejo que a maioria dos casais tem problema com ciúme, proibir, e a gente geralmente faz tudo junto ou temos abertura de um fazer e o outro não". Miguel indicou a rotina do casal era bem organizada e cada um tinha seu papel: "em casa tem a divisão de tarefas... . . . Bonitinho, divididinho. Não tem aquele que é o escravo, daí a gente não cria conflito".

A respeito da comunicação entre o casal, eles ressaltaram a diferença entre lidar com as situações já que Vicente era mais introspectivo no dia a dia, com dificuldade de falar o que aconteceu, enquanto que o Miguel conversava mais. O casal não vivenciava muito conflito, mas que já havia se desentendido em algumas ocasiões por conta de ciúmes de ambos. A necessidade de negociação para a manutenção da conjugalidade foi apontada por ambos. Miguel indicou ser necessário aprender a ceder e Vicente completou dizendo que deveria haver um "consenso", com a capacidade de um "Se colocar no lugar do outro".

Quanto às semelhanças com os pais, Miguel respondeu que Vicente se parecia com o pai:

Tem vez dele se alterar e falar alto e eu falo para ele que eu não sou a mãe dele. . . . Ele é muito parecido com o pai dele, assim como eu acho que sou parecido um pouco com o meu pai. E eu acho que ele é um pouco ao contrário da mãe dele. A mãe dele é um pouco desapegada dele.

Quando Miguel falou da mãe de Vicente, este respondeu que ele e sua irmã sempre foram muito independentes: "Como vim pra cá pra estudar e morei sozinho, eu tinha que me virar. Tanto que ela veio só esses dias visitar, 10 anos depois".

No que se refere aos avós paternos, Miguel sabia que o avô era imigrante italiano, tendo sido muito severo, gerando a impressão de que "ele fazia filho pra trabalhar para ele" e recordou-se de sua mãe relatar que o avô materno era agressivo, além de fazer uso de álcool. Indicou assemelhar-se a seu pai, visto como "meio cricrizinho". Vicente conta que os avós maternos e paternos se conheceram trabalhando na área rural, com os avós paternos tendo se casado cedo e a avó sendo mãe bem jovem, com o casal se separando depois. Os avós maternos mudaram constantemente de cidade em decorrência do trabalho na lavoura. Os pais de Vicente se separaram quando ele era adolescente, atribuindo a separação ao fato do pai ser severo e agressivo. Eram distantes, mas na atualidade se davam bem.

\section{Casal 4 - Clara (41) e Manuela (25)}

O casal, juntos há três anos, se conheceu por meio de uma amiga em comum que fazia faculdade com Clara, tendo começado o relacionamento logo após Clara se separar do ex-marido, com o início da relação poucos dias após Clara 
sair de casa: "Foi meio meteórico". No que se refere à escolha de parceira, Manuela falou sobre sua preferência por mulheres mais velhas como um fator para ficar com Clara, diferentemente de Clara que, diante da separação, não esperava se envolver com ninguém.

Sobre a escolha de viverem juntas, Manuela relatou que a situação fez com que elas morassem juntas, após seis meses de namoro. Indicaram que a mãe de Manuela reagiu "super bem" ao saber do relacionamento, ao contrário de Clara que experimentou uma reação negativa dos familiares, haja vista estar saindo de um relacionamento e assumindo sua orientação sexual. Ela já havia tentado assumir-se homossexual aos 18 anos, tendo apanhado da irmã e da mãe, que ameaçou se matar. Acabou se casando aos 23 anos, fato que acalmou a família e os boatos na cidade, mas acarretou no uso de álcool "pra poder aliviar", além de insônia, dor de cabeça, asma, com a saúde refletindo seu estado emocional. Tentou se desligar deste relacionamento quando o filho tinha três anos, sem tê-lo feito por se recordar da saída de seu pai de casa quando ela era pequena e da raiva gerada nela por ele tê-la deixado com a mãe que era uma pessoa extremamente difícil. Quando o filho chegou aos 15 anos, conversaram e ele incentivou-a a se separar, com a mãe e irmã novamente se opondo à escolha.

Sobre as expectativas quanto ao relacionamento, Manuela disse: "A Clara é meio cricri, né? Então já imaginei que não seria fácil" e Clara explicou dizendo:

Quando ela fala cricri, é por causa da organização da casa... . . . Naquela tentativa de manter tudo certinho, organizadinho, dentro daquele casamento, dentro daquela caixinha, eu fiquei neurótica com coisas da casa. Ai quando eu fui morar com a Manuela eu tive que desaprender muitas coisas.

Relacionavam-se muito bem, com brigas esporádicas, contudo Clara retomou as dificuldades passadas, especialmente as financeiras, vivenciadas em conjunto. Manuela era muito ciumenta, mas que como Clara não havia namorado muitas pessoas o relacionamento dava certo. Manuela assinalou também que ela era difícil, chegando a brigar por coisas bobas.
Manuela contou que costumava ficar quieta e achava que não ia dar certo, por ser uma pessoa difícil.

Pensavam em se comprar uma casa, se casar e, segundo Clara, ela desejar convencer Manuela a ter um filho, assinalando o medo do parto apresentado pela parceira. Ambas concordaram que era necessário confiança uma na outra para que o relacionamento pudesse ser mantido. Em relação à idade, Manuela afirmou: "Nem parece ter uma diferença de idade".

Quanto à semelhança com os pais, Manuela disse não perceber: "meu padrasto é muito possessivo. Não acho nem um pouco que meu relacionamento é parecido com o da minha mãe e meu padrasto". Clara, por sua vez, relatou uma semelhança com o pai.

Acho que nunca fui tão parecida com meu pai como agora. Não tanto no relacionamento, mas a experiência de ter sido execrado pela família. Ele por causa da doença que é o alcoolismo e eu por causa da homossexualidade, que na cabeça deles, eles veem como ismo.

Clara contou, sobre os avós paternos, que eles mudaram de cidade em decorrência da avó ter se casado com o melhor amigo do antigo noivo, após receberem a notícia, incorreta, sobre a morte deste noivo na guerra. Sobre os avós maternos, Clara relatou que a avó era retirante, vinda para trabalhar nas lavouras de café do sudeste do país, tendo se casado com o filho do administrador da fazenda na qual trabalhava. A relação de Clara com a avó era bastante próxima, com última tendo exercido uma função materna para Clara. Quanto aos pais, indicou que seus pais namoraram por oito meses, já se casaram, vivendo bem até quando Clara tinha dez anos de idade. O pai era alcoolista, desde o namoro, tendo saído de casa e retornado anos depois.

Sobre os avós paternos Manuela não possuía dados e quanto aos avós maternos, relatou que sua avó estava casada com outro homem que ela chamava de vô, sem nunca ter tido conhecimento de seu avô biológico. Acerca da história do relacionamento de seus pais, Manuela explicou que não possuía muito contato com o pai, pois ele e sua mãe nunca haviam sido casados. 


\section{Discussão}

Optou-se por apresentar uma discussão conjunta das quatro entrevistas, evidenciando aspectos próprios de cada casal, semelhanças e diferenças entre eles, com indicações relativas à tipologia vincular, dinâmica conjugal e influências da transmissão psíquica geracional na conjugalidade dos entrevistados. Neste sentido, nota-se que em todos os casais houve uma rapidez para se estabelecer o vínculo, assim como para morarem juntos. O Casal 2 atribuiu a rapidez, além do afeto, ao fato de serem lésbicas, posicionamento que aponta para a construção neste casal de uma identidade homoafetiva, apontando para o que compreendem ser características deste arranjo amoroso. Bernardo (Casal 1), por sua vez, relatou sempre explicar que seu relacionamento com Ícaro era como qualquer outro (Kurdek, 2004, 2005) e que as pessoas viam os relacionamentos homoafetivos como promíscuos, apontando para o estigma social vivenciado a partir da orientação sexual e que pode trazer consequências negativas para o casal (Doyle \& Molix, 2015; Esteca, 2016; Rostosky \& Riggle, 2017).

A família, por sua vez, possui papel importante na vivência da homoafetividade. Ícaro (Casal 1), Helena (Casal 2), Miguel (Casal 3) e Clara (Casal 4) relataram enfrentar dificuldades ao contar para família a respeito da orientação sexual. Percebe-se, portanto, a influência das expectativas parentais e o contrato narcisista (Aulagnier, 1979; Freud, 1914/1996; Monti, 2008) na vida destes indivíduos, uma vez que assumir a homossexualidade seria equivalente a romper com este contrato inconsciente e possivelmente com o vínculo familiar como o exposto por Clara que se sentia execrada pela família. A influência dos padrões heteronormativos no discurso das famílias (Esteca, 2016) e os conflitos intensos advindos desta necessidade de adequação aos padrões podem ser percebidos em nos casos de Miguel (Casal 3) e Clara (Casal 4), que estiveram em relacionamentos heterossexuais prévios, apesar de já reconhecerem em si um desejo por parceiros do mesmo sexo.
O início do relacionamento do Casal 1 esteve marcado por uma grande dependência emocional, pois relataram que não conseguiam viver sem o outro, podendo-se pensar em uma estrutura de vínculo dual (Puget \& Berenstein, 1993), na qual há uma indiscriminação no vínculo, uma necessidade de referir-se ao outro para sentirem-se incluídos. Contudo, com o amadurecimento do casal, conseguiam planejar a entrada de um terceiro elemento ao relatarem o desejo da parentalidade, podendo-se apontar para o estabelecimento de um vínculo de terceiridade, sem dados para caracterização dela como terceridade limitada ou ampla. O Casal 2, por sua vez, realçou as diferenças entre as parceiras. Helena afirmou que havia uma compreensão mútua acerca da possibilidade de dedicação a atividades individuais, cuidando, contudo, para o desenvolvimento de espaços em comum para partilhar a conjugalidade, com uma cotidianeidade, planos partilhados entre ambas, com aparente equilíbrio entre o individual e o conjugal. Tal dinâmica pode remeter a uma relação do tipo terceiridade ampla (Puget \& Berenstein, 1993), pois evidencia a presença da comunicação a fim de elaborar os conflitos vivenciados, a preservação e respeito à individualidade de cada uma.

O Casal 3 também evidenciou que ambos possuíam atitudes diferentes quanto ao relacionamento, mas que conseguiam chegar a um acordo. Não havia um vínculo mantido pela idealização, uma vez que cada um também apontou para coisas no outro que não o agradava, podendo-se pensar em uma estrutura de terceiridade ampla (Puget \& Berenstein, 1993). Acredita-se que o Casal 4 também se organizou em torno de uma tipologia de terceiridade ampla, haja vista que ambas relataram como se percebiam e como percebiam a outra, evidenciando contudo, suas diferenças e o respeito ao outro, com as concessões necessárias à vivência em conjunto.

As marcas geracionais puderam ser observadas em diversos momentos, como no Casal 1 cujo relacionamento se iniciou de maneira semelhante aos dos pais de Bernardo, uma vez que ambos desistiram de seus relacionamentos anteriores para se vincularem. Clara (Casal 
4) afirmou que fazia uso de álcool durante seu primeiro casamento e desejando sair de casa, tal como seu próprio pai, aspecto observado por ela própria. Miguel (Casal 3) contou que costumava implicar com as coisas, semelhante ao seu genitor, tendo inclusive apontado semelhanças de seu cônjuge Vicente com o pai, lembrando da escolha anaclítica proposta por Freud (1914/1996). Alice (Casal 2) explicou que não era uma pessoa que costumava falar muito, tendo relacionado esse fator à dinâmica de sua família. O contrário acontecia com Helena, que afirmou ter uma família comunicativa. Tais aspectos citados relacionam-se àquilo que é transmitido psiquicamente entre as famílias, seja no que se refere a aspectos conscientes, com a família de origem como um modelo de identificação, seja por meio de conteúdos inconscientes, com influência de pactos inconscientes (Kaës, 2014) e da transmissão psíquica transgeracional (Scorsolini-Comin \& Santos, 2016).

As histórias familiares de quase todos os participantes foram permeadas por conflitos, que imprimiram marcas nos relacionamentos. Entretanto, observa-se de uma maneira geral que os casais não enfrentavam ou haviam enfrentado situações tão adversas quanto de suas famílias pregressas. Ícaro (Casal 1) referiu-se à relação com Bernardo como "amadurecida". Helena (Casal 2) rejeitava o passado conflituoso dos pais, mas indicava semelhança quanto à forte parceria estabelecida com Alice. Miguel e Vicente (Casal 3) buscavam se entender e estabelecer um consenso entre os dois quando vivenciavam brigas. Clara e Manuela (Casal 4) faziam acordos a respeito da dinâmica da casa e relataram conviver de maneira harmoniosa.

Considera-se que esses casais traziam para a conjugalidade elementos de suas famílias de origem (Merli, 2012), contudo, parecendo ter se apropriado e elaborado parte desta herança (Paiva \& Gomes, 2012; Scorsolini-Comin \& Santos, 2016), buscando criar um modelo conjugal próprio (Rodriguez et al., 2017). Apesar das particularidades de cada casal, pode-se apontar para a presença de uma tipologia vincular mais amadurecida, do tipo terceiridade, quando há condições de comportar as diferenças existentes entre os membros, sem a vivência de fusão característica da estrutura dual (Puget \& Berenstein, 1993). Reforça-se, assim, os questionamentos acerca de possíveis traços psicopatológicos e olhares estereotipados que podem ser atribuídos a esta população (Munhoz, 2017).

Por fim, pensa-se que casais de pessoas do mesmo sexo acabam por enfrentar situações com as quais casais de heterossexuais não passariam, como por exemplo a não aceitação da família quando esta é advinda especificamente da homoafetividade, como aponta Esteca (2016), indicando que este fato por implicar em consequências negativas para o relacionamento afetivo. Lembra-se que as dificuldades enfrentadas pelos casais homoafetivos se estendem para além do contexto familiar, com problemáticas também centradas no cenário social, onde nem sempre o relacionamento pode ser assumido de forma livre, aberta. Ou seja, para além da não aceitação do cônjuge por parte da família, algo que pode ocorrer em casais heterossexuais, compreende-se que esta rejeição vem carregada de outras implicações advindas do campo social. Neste sentido, acredita-se que se a expressão do afeto no espaço público pode se apresentar como algo cerceado para estes casais, tem-se impedimentos em relação à aceitação e possibilidade de expressão da afetividade também no campo privado, familiar. Tal fato pode implicar em sofrimento psíquico deste público, não decorrente da tipologia vincular estabelecida no par amoroso, mas decorrente de fatores extrínsecos à relação.

De forma geral, os padrões heteronormativos estão ainda muito presentes, seja no próprio delineamento de pesquisas que almejam a comparação entre casais homoafetivos e heterossexuais (Nascimento et al., 2015; Rodrigues \& Boeckel, 2016), seja no próprio relacionamento estabelecido (Munhoz, 2017), refletindo-se sobre diferentes maneiras para a construção da conjugalidade, busca apontada pelos casais estudados. Entende-se, assim, que casais homoafetivos estão inseridos em contextos diferenciados e, portanto, necessitam de estudos que contemplem suas vivências (Nascimento et al., 2015). Como defendido por Rodrigues e Boeckel (2016, p. 107) "a compreensão e a reflexão das 
diversas formas de conjugalidades para além do modelo tradicional heteronormativo podem ser de grande relevância nas ações interventivas em Psicologia", ressaltando-se a importância para a clínica deste esmiuçamento acerca da dinâmica destes casais.

Contudo, reconhece-se a existência de limitações concernentes ao tamanho e heterogeneidade da amostra, composta por apenas quatro casais - dois de mulheres e dois de homens - além da não abordagem de elementos relativos à classe socioeconômica, raça e religião, compreendendo-os como aspectos que podem influenciar na natureza dos dados coletados. Os limites também se referem ao fato dos dados terem sido obtidos por meio de uma única entrevista em profundidade que, a despeito dos ganhos para os casais advindos da entrevista em conjunto (Merli, 2012), que proporciona conhecimento sobre histórias pregressas, discussão sobre a conjugalidade e apropriação de conteúdos antes não sabidos, se configura como um recorte desta vivência, algo diferente daquilo que ocorre quando se trata de um material clínico advindo de um processo psicoterapêutico com estes casais. Assim, não se buscou uma análise fechada dos dados e sim uma discussão que fomentasse o interesse no empreendimento de novos estudos.

No que se refere às propostas de estudos com populações similares, propõe-se investigações que trabalhem com amostras mais amplas, que possam comparar resultados tendo em vista classe socioeconômica, raça e religião. Compreende-se ser igualmente pertinente o desenvolvimento de estudos que façam uso de material clínico advindo da psicoterapia de casal com este público ou por meio de entrevistas com psicoterapeutas de casal que atendam casais homoafetivos, enriquecendo a compreensão da dinâmica conjugal destes casais.

\section{Referências}

Aulagnier, P. (1979). A violência da interpretação. Rio de Janeiro, RJ: Imago.

Cecílio, M. S., Scorsolini-Comin, F., \& Santos, M. A. (2013). Produção científica sobre adoção por casais homossexuais no contexto brasileiro. Estudos de Psicologia (Natal), 18(3), 507516. doi: https://dx.doi.org/10.1590/S1413$-294 X 2013000300011$

Cerqueira-Santos, E., \& Santana, G. (2015). Adoção homoparental e preconceito: Crenças de estudantes de direito e serviço social. Temas em Psicologia, 23(4), 873-885. doi: http://dx.doi. org/10.9788/TP2015.4-06

Conselho Nacional de Justiça. (2013, 14 maio). Resolução $n^{\circ} 175$ de 14/05/2013. Dispõe sobre a habilitação, celebração de casamento civil, ou de conversão de união estável em casamento, entre pessoas de mesmo sexo. Recuperado em http://www.cnj.jus.br/busca-atos-adm?documento $=2504$

Defendi, E. L. (2010). Homoconjugalidade masculina, revelação e redes sociais: Um estudo de caso (Dissertação de mestrado em Psicologia Clínica, Pontifícia Universidade Católica de São Paulo, SP, Brasil).

Doyle, D. M., \& Molix, L. (2015). Social stigma and sexual minorities' romantic relationship functioning: A meta-analytic review. Personality and Social Psychology Bulletin, 41(10), 1363-1381. doi: http://journals.sagepub.com/ doi/10.1177/0146167215594592

Esteca, F. M. (2016). Impactos da heteronormatividade sobre a conjugalidade lésbica: Uma análise psicanalítica a partir do relato de mulheres separadas (Tese de doutorado em Psicologia Clínica, Universidade de São Paulo, SP, Brasil).

Féres-Carneiro, T. (1997). A escolha amorosa e interação conjugal na heterossexualidade e na homossexualidade. Psicologia: Reflexão e Crítica, 10(2), 351-368. doi: http://dx.doi.org/10.1590/ S0102-79721997000200012

Fontanella, B. J. B., \& Magdaleno, R., Jr. (2012). Saturação teórica em pesquisas qualitativas: Contribuições psicanalíticas. Psicologia em Estudo, 17(1), 63-71. doi: https://dx.doi.org/10.1590/ S1413-73722012000100008

Freud, S. (1996). Sobre o narcisismo: Uma introdução. In S. Freud, Obras psicológicas completas de Sigmund Freud: Edição standard brasileira (pp. 81-108). Rio de Janeiro, RJ: Imago. (Original publicado em 1914)

Gato, J., \& Fontaine, A. M. (2014). Homoparentalidade no masculino: Uma revisão da literatura. Psicologia \& Sociedade, 26(2), 
312-322. doi: https://dx.doi.org/10.1590/S010271822014000200008

Kaës, R. (2011). A realidade psíquica do vínculo. Revista Brasileira de Psicanálise, 45(4), 155-166.

Kaës, R. (2014). As alianças inconscientes. São Paulo, SP: Idéias \& Letras.

Kurdek, L. A. (2004). Are gay and lesbian cohabiting couples really different from heterosexual married couples?. Journal of Marriage and Family, 66(4), 880-900. doi: https://doi.org/10.1111/ j.0022-2445.2004.00060.x

Kurdek, L. A. (2005). What do we know about gay and lesbian couples?. Current Directions in Psychological Science, 14(5), 251-254. doi: https:// doi.org/10.1111/j.0963-7214.2005.00375.x

Lima, J. E. A. (2014). Homoafetividade sob a ótica do direito no Brasil. Critério Jurídico, 14(1), 44-69. Recuperado em http://revistas.javerianacali.edu.co/index.php/criteriojuridico/article/ view/1124/1711

Lira, A. N., \& Morais, N. A. (2016). Famílias constituídas por lésbicas, gays e bissexuais: Revisão sistemática de literatura. Temas em Psicologia, 24(3), 1051-1067. doi: https://dx.doi. org/10.9788/TP2016.3-14Pt

Lira, A. N., Morais, N. A., \& Boris, G. D. J. B. (2015). A homoparentalidade em cena: A vivência cotidiana de mulheres lésbicas com seus filhos. $R e$ vista da SPAGESP, 16(1), 74-91. Recuperado em http://pepsic.bvsalud.org/scielo.php?script=sci_ arttext\&pid=S1677-29702015000100007

Lomando, E., Wagner, A., \& Gonçalves, J. (2011). Coesão, adaptabilidade e rede social no relacionamento conjugal homossexual. Psicologia: Teoria e Prática, 13(3), 96-109. Recuperado em http://pepsic.bvsalud.org/scielo.php?script=sci arttext\&pid=S1516-36872011000300008\&lng= pt\&tlng $=p t$

Merli, L. F. (2012). Quando a conjugalidade surge antes da parentalidade (Dissertação de mestrado, Instituto de Psicologia, Universidade de São Paulo, SP, Brasil).

Monti, M. R. (2008). Contrato narcisista e clínica do vazio. Revista Latinoamericana de Psicopatologia Fundamental, 11(2), 239-253. doi: http:// dx.doi.org/10.1590/S1415-47142008000200006

Moraes, R. (2003). Uma tempestade de luz: A compreensão possibilitada pela análise textual discursiva. Ciência \& Educação (Bauru), 9(2),
191-211. doi: https://dx.doi.org/10.1590/S151673132003000200004

Munhoz, D. B. (2017). A constituição do vínculo e o legado familiar heteronormativo em casais homossexuais longevos, femininos e masculinos (Tese de doutorado em Psicologia Clínica, Universidade de São Paulo, SP, Brasil).

Nascimento, G. C. M., Scorsolini-Comin, F., Fontaine, A. M. G. V., \& Santos, M. A. (2015). Relacionamentos amorosos e homossexualidade: Revisão integrativa da literatura. Temas em Psicologia, 23(3), 547-563. doi: https://dx.doi. org/10.9788/TP2015.3-03

Nascimento, M. (2015). "O amor entre iguais também forma família": Uma experiência de trabalho com famílias homoafetivas. Nova Perspectiva Sistêmica, 24(51), 127-129. Recuperado em http:/www.revistanps.com.br/index.php/nps/ article/view/181/156

Paiva, M. L. S. C., \& Gomes, I. C. (2012). La transmission psychique et la constitution du lien conjugal. Revue de Psychothérapie Psychanalytique de Groupe, 58(1), 81-90. doi: https:// dx.doi.org/10.3917/rppg.058.0081

Pontes, M. F., Féres-Carneiro, T., \& Magalhães, A. S. (2015). Famílias homoparentais e maternidade biológica. Psicologia \& Sociedade, 27(1), 189-198. doi: https://dx.doi.org/10.1590/1807$-03102015 \mathrm{v} 27 \mathrm{n} 1 \mathrm{p} 189$

Puget, J., \& Berenstein, I. (1993). Psicanálise do casal. Porto Alegre, RS: Artes Médicas.

Ramos, D. P., Jr., \& Benigno, E. P. (2013). Casamento homoafetivo no Direito Brasileiro e no Direito Comparado: Tendências segundo uma visão histórica, econômica e antropológica. Revista Jurídica Cesumar-Mestrado, 13(2), 581-609. doi: http://dx.doi.org/10.17765/2176$-9184.2013 \mathrm{v} 13 \mathrm{n} 2 \mathrm{p} \% 25 \mathrm{p}$

Rodrigues, V., \& Boeckel, M. (2016). Conjugalidade e homossexualidade: Uma revisão sistemática de literatura. Nova Perspectiva Sistêmica, 25(55), 96-109. Recuperado em http://www.revistanps. com.br/index.php/nps/article/view/138/142

Rodriguez, B. C., \& Gomes, I. C. (2012). Novas formas de parentalidade: Do modelo tradicional à homoparentalidade. Boletim de Psicologia, 62(136), 29-36. Recuperado em http:// pepsic.bvsalud.org/scielo.php? script $=\mathrm{sci}_{-}$ arttext\&pid=S0006-59432012000100004\&lng= pt\&tlng=pt 
Rodriguez, B. C., Gomes, I. C., \& Oliveira, D. P. (2017). Família e nomeação na contemporaneidade: Uma reflexão psicanalítica. Estudos Interdisciplinares em Psicologia, 8(1), 135-150. doi: http://dx.doi.org/10.5433/2236$-6407.2017 \mathrm{v} 8 \mathrm{n} 1 \mathrm{p} 135$

Rodriguez, B. C., Merli, L. F., \& Gomes, I. C. (2015). Um estudo sobre a representação parental de casais homoafetivos masculinos. Temas em Psicologia, 23(3), 751-762. doi: https://dx.doi. org/10.9788/TP2015.3-18

Rostosky, S. S., \& Riggle, E. D. (2017). Same-sex relationships and minority stress. Current Opinion in Psychology, 13, 29-38. doi: https://doi. org/10.1016/j.copsyc.2016.04.011

Santos, C. V. M., \& Gomes, I. C. (2016). The L Word - Discussões em torno da parentalidade lésbica. Psicologia: Ciência e Profissão, 36(1), 101-115. doi: https://dx.doi.org/10.1590/19823703000092014

Santos, Y. G. S., Scorsolini-Comin, F., \& Santos, M. A. (2013). Homoparentalidade masculina: Revisando a produção científica. Psicologia: Reflexão e Crítica, 26(3), 572-582. doi: https://dx.doi. org/10.1590/S0102-79722013000300017

Scorsolini-Comin, F., \& Santos, M. A. (2016). Construir, organizar, transformar: Considerações teóricas sobre a transmissão psíquica entre gerações. Psicologia Clínica, 28(1), 141159. Recuperado em http://pepsic.bvsalud. org/scielo.php?script $=$ sci_arttext\&pid $=$ S0103$-56652016000100008 \& \operatorname{lng}=\mathrm{pt} \& \operatorname{tlng}=\mathrm{pt}$

Silva, M. M. L., Frutuozo, J. F. F., Feijó, M. R., Valerio, N. I., \& Chaves, U. H. (2015). Família e orientação sexual: Dificuldades na aceitação da homossexualidade masculina. Temas em Psicologia, 23(3), 677-692. doi: https://dx.doi. org/10.9788/TP2015.3-12
Turato, E. R. (2003). Tratado da metodologia da pesquisa clínico-qualitativa: Construção teórico-epistemológica, discussão comparada e aplicação nas áreas da saúde e humanas. Petrópolis, RJ: Vozes.

Vareschini, J. M. L. (2009). O reconhecimento jurídico da união entre pessoas do mesmo sexo. $\mathrm{Ca}$ dernos da Escola de Direito e Relações Internacionais, 2(11), 302-340. Recuperado em http:// revistas.unibrasil.com.br/cadernosdireito/index. $\mathrm{php} /$ direito/article/view/757/711

Vilhena, J., Souza, A. C. B., Uziel, A. P., Zamora, M. H., \& Novaes, J. V. (2011). Que família?: Provocações a partir da homoparentalidade. Revista Mal Estar e Subjetividade, 11(4), 16391658. Recuperado em http://pepsic.bvsalud. org/scielo.php?script $=$ sci_arttext\&pid $=\mathrm{S} 1518$ $-61482011000400014 \& \operatorname{lng}=\mathrm{pt} \& \operatorname{tlng}=\mathrm{pt}$

Zanetti, S. A. S. (2013). O método psicanalítico: Quando a pesquisa pode contar com uma escuta permeável ao inconsciente. In Anais do I Encontro de Pesquisa Clínico-Qualitativa e I Jornada do LEPPSI: Interlocução de saberes, desafios e descobertas na trajetória da pesquisa (pp. 2530). Londrina, PR: Universidade Estadual de Londrina.

Zanetti, S. A. S., \& Gomes, I. C. (2013). Vínculos amorosos contemporâneos frágeis. OMNIA Saúde, 10(1), 36-45. Recuperado em http://www. fai.com.br/portal/ojs/index.php/omniasaude/article/view/465/645

Recebido: 03/01/2017

$1^{a}$ revisão: $10 / 07 / 2017$

$2^{a}$ revisão: $23 / 10 / 2017$

$3^{a}$ revisão: 04/12/2017

Aceite final:21/02/2018

(c) BY (c) O(s) autor(es), 2018. Acesso aberto. Este artigo está distribuído nos termos da Licença Internacional Creative Commons Atribuição 4.0 (http://creativecommons.org/licenses/by/4.0/), que permite o uso, distribuição e reprodução sem restrições em qualquer meio, desde que você dê crédito apropriado ao(s) autor(es) original(ais) e à fonte, fornecer um link para a licença Creative Commons e indicar se as alterações foram feitas. 